This is a preprint or reprint of a paper presented at a conference. Since revisions may be made prior to formal publication, this version is made available with the understanding that it will not be cited or reproduced without the permission of the author.

\title{
GT2005-69132
}

\section{THE EFFECT OF ULTRAPOLISH ON A TRANSONIC AXIAL ROTOR}

\author{
William B. Roberts \\ Airfoil Technologies International and \\ Flow Application Research \\ Freemont California, USA \\ Scott Thorp \\ NASA-Glenn Research Center \\ Cleveland, Ohio, USA
}

\author{
Patricia S. Prahst \\ AP Solutions \\ Solon, Ohio, USA
}

\author{
Anthony J. Strazisar \\ NASA-Glenn Research Center \\ Cleveland, Ohio, USA
}

\begin{abstract}
Back-to-back testing has been done using NASA fan rotor 67 in the Glenn Research Center W8 Axial Compressor Test Facility. The rotor was baseline tested with a normal industrial RMS surface finish of 0.5-0.6 $\mu \mathrm{m}$ (20-24 microinches) at 60, 80 and $100 \%$ of design speed. At design speed the tip relative Mach number was 1.38. The blades were then removed from the facility and ultrapolished to a surface finish of $0.125 \mu \mathrm{m}$ (5 microinch) or less and retested.
\end{abstract}

At $100 \%$ speed near the design point, the ultrapolished blades showed approximately $0.3-0.5 \%$ increase in adiabatic efficiency. The difference was greater near maximum flow. Due to increased relative measurement error at 60 and $80 \%$ speed, the performance difference between the normal and ultrapolished blades was indeterminate at these speeds.

\section{INTRODUCTION}

As fuel costs continue to increase, the industries that use gas turbine engines have a pressing need to improve in-service performance. This need is especially true in the airline industry, for which fuel burn and performance retention in high by-pass ratio turbofan engines is a major concern. Any approach to improve the efficiency of present equipment will be considered if cost effective.

Previous research by Suder et.al. [1] has shown that surface finish of axial fan and compressor blading is very important. This earlier research indicates that there is a significant performance penalty if the surface finish degrades from an industry-standard RMS finish of $0.5-0.6 \mu \mathrm{m} \quad(20-24$ microinches) to a finish of 2.5-3.0 $\mu \mathrm{m}$ (100-125 microinches).
Figure 1, taken from Suder et.al. [1], shows the impact of surface roughness of 2.5-3.0 $\mu \mathrm{m}$ on the design speed performance of a transonic compressor rotor. The six configurations shown in this figure differ in the location of roughness on the blade surface. One key finding from this work was that surface roughness on the leading edge of the blade, which exists for configurations $\mathrm{G}, \mathrm{H}$, and I, causes the most severe performance penalty. Suder's work leads to the question of whether or not a gain in efficiency could be achieved if axial fan and compressor blade surfaces are polished to finishes less than 0.5-0.6 $\mu \mathrm{m}$.

According to Koch and Smith [2], the blade surface is considered hydraulically smooth for equivalent sand roughness Reynolds number less than 90. In theory, a better (lower RMS) finish than hydraulically smooth offers no benefit to performance. The standard industry surface finish of 0.5-0.6 $\mu \mathrm{m}$ is typically near or less than a roughness Reynolds number of 90 at high altitude cruise operating conditions where most fuel burn occurs. At the test conditions used in this work, a surface finish of $0.125 \mu \mathrm{m}$ (5.0 microinches) corresponds to a roughness Reynolds number of approximately 20. Therefore, there is some justified skepticism as to whether ultrapolish, defined as a surface finish of $0.125 \mu \mathrm{m}$ or better, can improve efficiency. However, occasional airline trials with ultrapolished blading have indicated that ultrapolishing is beneficial in that lower fuel burn is observed during acceptance testing after engine refurbishment. To verify and quantify the impact of ultrapolished surface finish on blade performance, back-to-back testing was done in the NASA Glenn Research Center's W8 Axial Compressor Test Facility using NASA fan rotor 67. Baseline testing at a nominal surface finish of $0.5 \mu \mathrm{m}(20$ microinches) was followed by testing with the blades 


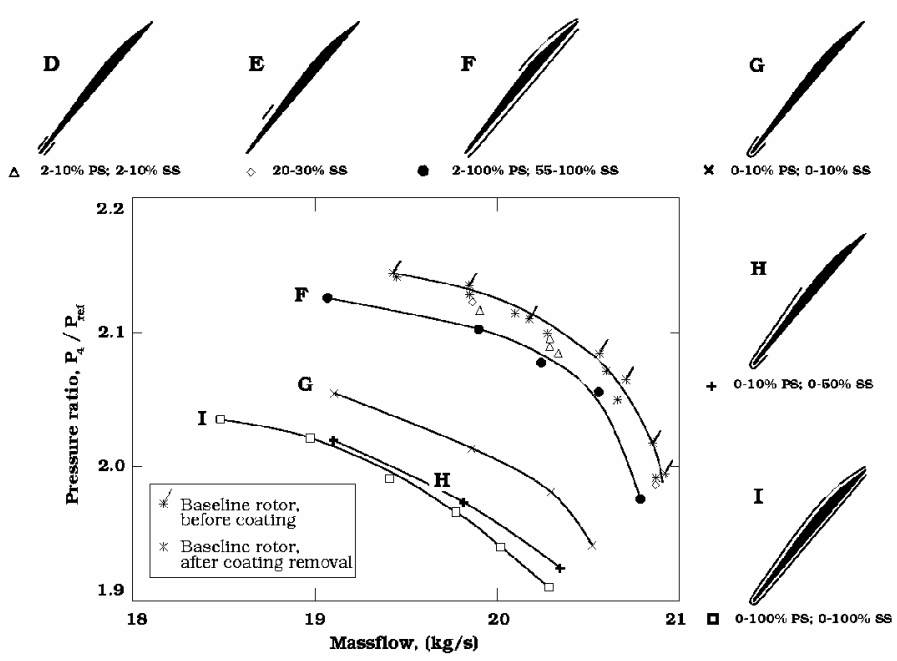

Figure 1. Pressure rise characteristics of a transonic compressor rotor as a function of the extent of surface roughness, from Suder [1].

ultrapolished to $0.125 \mu \mathrm{m}$ ( 5 microinches) or better at 60,80 and $100 \%$ of design speed.

\section{TEST ROTOR}

NASA Rotor 67 is shown in Figure 2. It is a low-aspect-ratio design and the first-stage rotor of a two-stage fan. A complete description of the aerodynamic design of the full two-stage fan is given in [3] and [4].

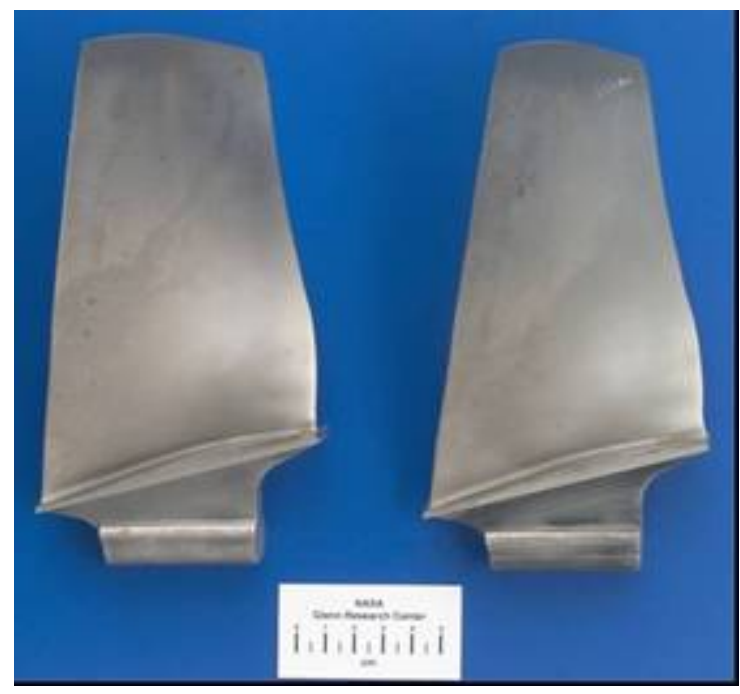

Figure 2. NASA fan rotor 67.

The rotor design pressure ratio is 1.63 at a mass flow of 33.35 $\mathrm{kg} / \mathrm{sec}$. The design rotational speed is $16,043 \mathrm{rpm}$, which yields a tip speed of $429 \mathrm{~m} / \mathrm{sec}$ and an inlet tip relative Mach number of 1.38. The rotor has 22 blades and an aspect ratio of 1.56 (based on average span/root axial chord). The rotor solidity varies from 2.11 at the hub to 1.29 at the tip. The inlet and exit tip diameters are 51.14 and $48.5 \mathrm{~cm}$ respectively, and the inlet and exit hub/tip radius ratios are 0.375 and 0.478 respectively. A fillet radius of $1.78 \mathrm{~mm}$ is used at the airfoilhub juncture. The square root of the mean square of the airfoil surface finish is $0.6 \mu \mathrm{m}$ ( 24 microinches) or better, the airfoil surface tolerance is $\pm 0.04 \mathrm{~mm}$, and the running tip clearance is approximately $0.5 \mathrm{~mm}$.

\section{TEST FACILITY}

A schematic diagram of the NASA Glenn Axial Flow Compressor Test Facility is shown in Figure 3. The drive system consists of a $7000 \mathrm{hp}$ electric motor with a variablefrequency power supply. Motor speed is controllable from 400 to $3600 \mathrm{rpm}$. The motor is coupled to a 5.25 gear ratio speed increaser gear box that in turn drives the rotor. The facility is sized for a maximum airflow of $45 \mathrm{~kg} / \mathrm{sec}$ with atmospheric air as the working fluid.

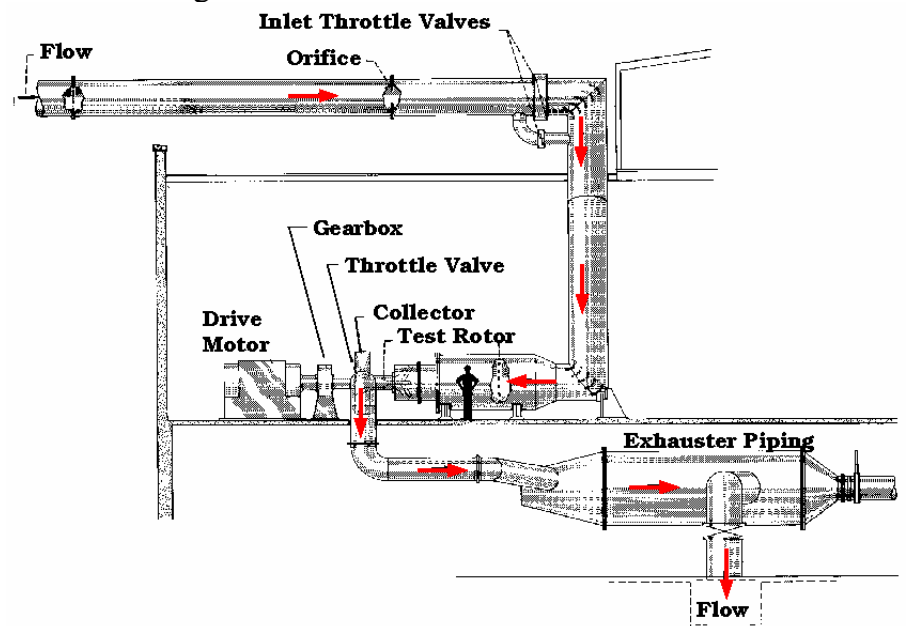

Figure 3. Schematic diagram of the NASA-Glenn Axial Compressor Test Facility.

Air is drawn into the facility from an inlet located on the roof of the building. The air first passes through a $10 \mu \mathrm{m}$ filter to remove large particles. An alternate dry-air source can also be used to supply air to the facility. This source was used in the present work to eliminate humidity variations between testing of the baseline and ultrapolished blading. The inlet air passes through a flow measuring station consisting of a thin-plate orifice, through inlet throttling valves, and into a settling chamber. The air is accelerated into the compressor test section through a nozzle, passes through the test rotor, and then passes through a sleeve valve into a collector before it is exhausted back into the atmosphere. The airflow is controlled through the sleeve valve.

\section{INSTRUMENTATION AND MEASUREMENT TECHNIQUES}

Massflow is measured using a calibrated orifice located far upstream of the compressor. The orifice measurements are corrected to standard-day conditions based on settling chamber temperature and pressure. Radial distributions of total and static pressure and flow angle are measured using rakes at stations 1 and 4 shown in Figure 4. Stage 67 was operated in a rotor-only mode without the stator installed in the present work. Station 4 , which is normally used to survey the stator outlet flow, is therefore the first available aerodynamic survey station downstream of the rotor. The rake measurements are corrected for streamline slope based on a calibration of each probe used and on the design streamline slope. All rake measurements are corrected to sea-level standard-day conditions in the settling 

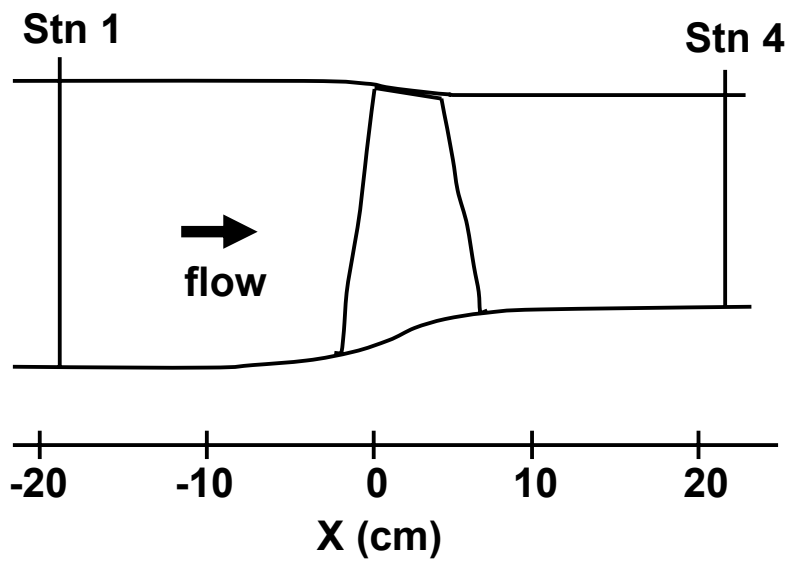

Figure 4. Location of aerodynamic survey measurement stations.

chamber. Radial distributions of total pressure are energy averaged by converting them to their enthalpy equivalents and then mass averaging them across the annulus. Rotor efficiency is determined using the pressure rise measured across the rotor and torque measured by a torque meter. Measurement uncertainties are: massflow, $\pm 0.11 \mathrm{~kg} / \mathrm{s}$; flow angle, \pm 0.5 degrees; total pressure, $\pm 0.01 \mathrm{~N} / \mathrm{cm}^{2}$; torque $\pm 11.5 \mathrm{~cm}-\mathrm{kg}(10$ in-lb).

\section{TEST RESULTS}

The compressor characteristics for Rotor 67 with the baseline and ultrapolish surface finish are shown for 60, 80, and $100 \%$ of design speed in Figure 5. Performance of the baseline configuration was not measured at flow rates near stall because of a concern on maintaining rotor balance during a stall. The performance was measured all the way to stall for the ultrapolished configurations at $80 \%$ and $100 \%$ speed.

The error bars in Figure 5 indicate estimated uncertainties in the calculated quantities based on a propagation of error analysis using the measurement uncertainties. The measurement uncertainties at $60 \%$ and $80 \%$ speed are large due to the decreased relative instrument sensitivity that results from the lower pressure rise and torque levels at these speeds. The differences in performance curves for $60 \%$ and $80 \%$ speed are small between the baseline and polished blades.

At $100 \%$ speed performance differences between the baseline and ultrapolished rotor are discernible and are larger than the measurement uncertainties. At design speed the results would seem to imply that the maximum flow capacity of the ultrapolished rotor is higher than that of the baseline rotor. We are not certain if this is true since the rotor was not yet choked at the lowest backpressure measured for either surface finish. We do note however that the trend toward higher flow capacity as the surface finish improves is consistent with the trend observed by Suder et al [1], as shown in Figure 1.

We also note that the pressure ratio at the design operating condition is significantly higher than the design value of 1.63 . This rotor was designed in the mid 1970's, before the availability of accurate turbomachinery performance prediction
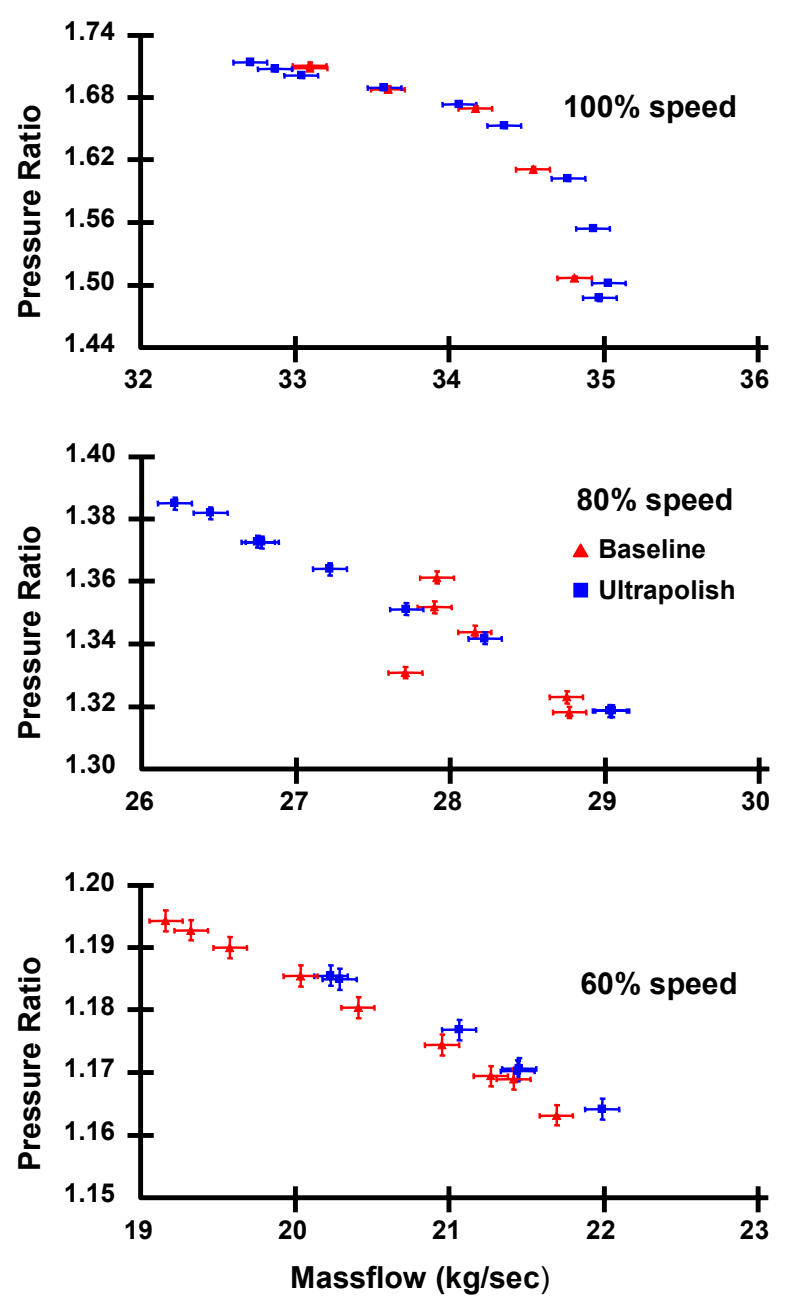

Figure 5. Pressure rise characteristics for baseline and ultrapolished surface finishes.

capability. The pressure ratio measured in the present work is consistent with that measured and predicted using 3D NavierStokes simulations for this rotor by Pierzga and Wood [5].

The main purpose of this research is to determine the difference in adiabatic efficiency between the baseline and ultrapolished blades. Figure 6 shows the torque-based efficiency plotted versus corrected mass flow for baseline and ultrapolished blades at 60, 80 and 100\% speed with error bars added. The actual rotor efficiency is higher than that shown here because this data has not been corrected for the tare torque of the rotor drive system.

\section{DISCUSSION}

The results in Figure 6 indicate that for $100 \%$ speed there is a noticeable difference between the baseline and ultrapolished adiabatic efficiency, with the ultrapolished blades showing a small but significant increase. Near the maximum efficiency operating condition, the difference is approximately one-half of one percent $(0.5 \%)$.

Although the results in Figure 6 indicate that the difference in efficiency is greater at higher mass flow conditions, transonic fans in service operate near maximum efficiency. Therefore, the improvement in performance seen by an engine in service 

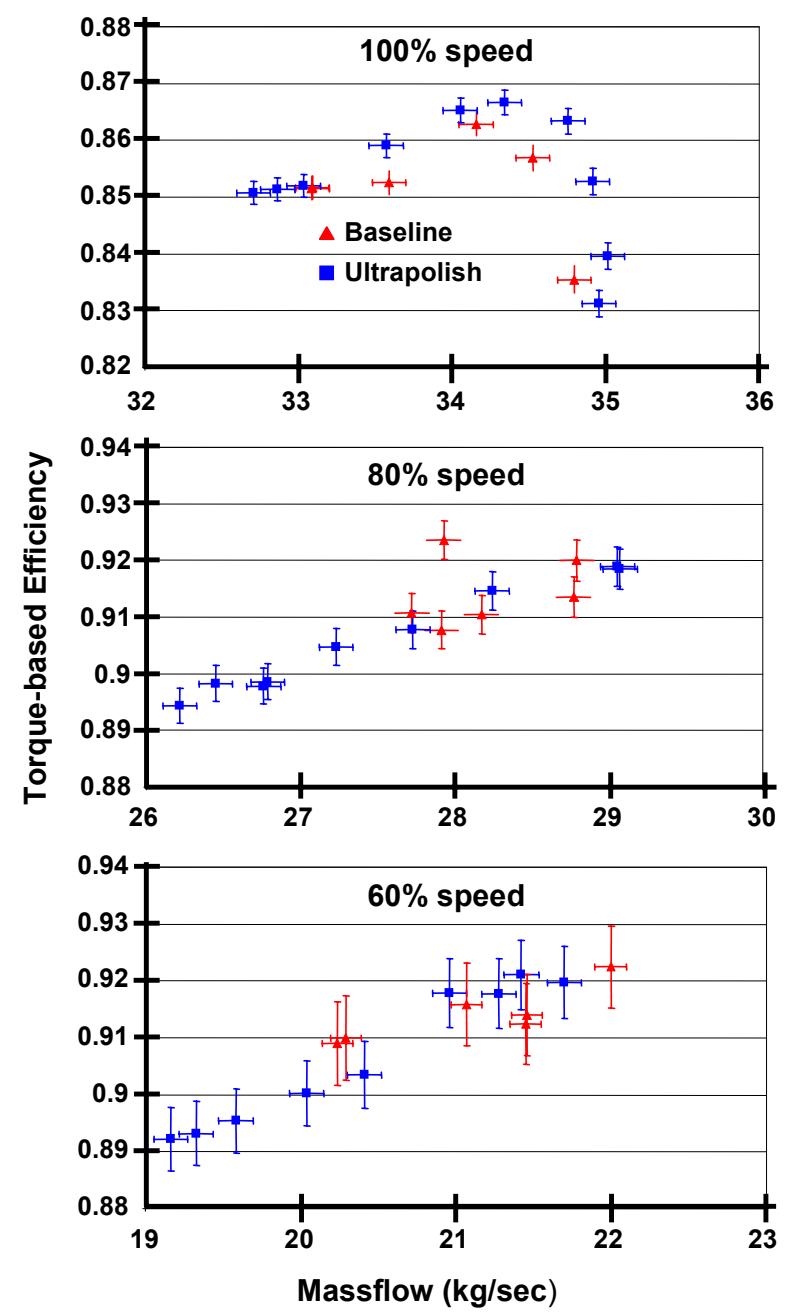

Figure 6. Adiabatic efficiency characteristics for baseline and ultrapolished surface finishes.

would likely be on the order of $0.5 \%$ rather than the larger values shown for higher mass flow. The larger efficiency differences observed at high mass flow rates are likely due to changes in the oblique rotor shock strength around the baseline and ultrapolished leading edge.

References [1] and [6] indicate that the leading edge of axial blading can have a significant impact on aerodynamic performance, with rough, oversized, or blunt leading edges significantly decreasing performance. Figure 7, taken from Roberts [6], shows the impact of fan blade leading edge shape on thrust specific fuel consumption of a high bypass ratio turbofan engine.

Figure 8 shows a photographic magnification of the leading edge of Rotor 67 before and after ultrapolish. Although the leading edge of the ultrapolished blade is not perfectly smooth, the surface finish is more uniform than the baseline leading edge. The ultrapolish process does remove a very small amount of material from the surface of the blade. Therefore, if the ultrapolish process improved the leading edge of the blades by smoothing or decreasing the thickness, all or part of the efficiency increase shown in Figure 6 could be from leading edge shape change.

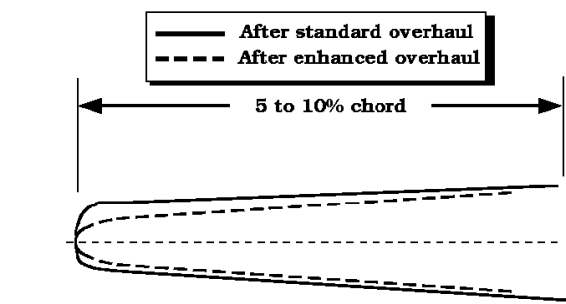

Blade leading edge shape before and after enhanced refurbishment.

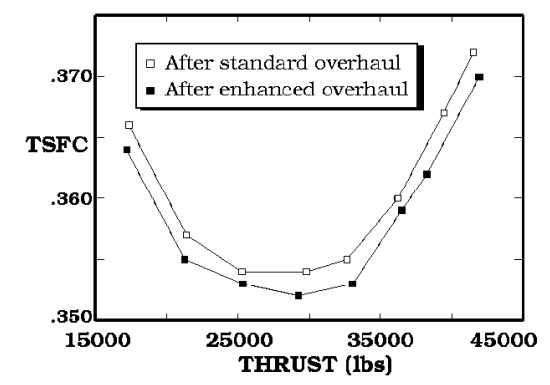

Comparison of thrust-specific fuel consumption before and after enhanced refurbishment.

Figure 7. Impact of leading edge shape on the thrust specific fuel consumption of a high bypass ratio turbofan engine, from Roberts [6].

To check the sensitivity of Rotor 67 performance to leading edge shape, a quasi three-dimensional computational analysis was performed on the blade geometry at 100 percent design speed. The 70 percent span location (from the hub) was chosen for this analysis since it is well outside the endwall region but

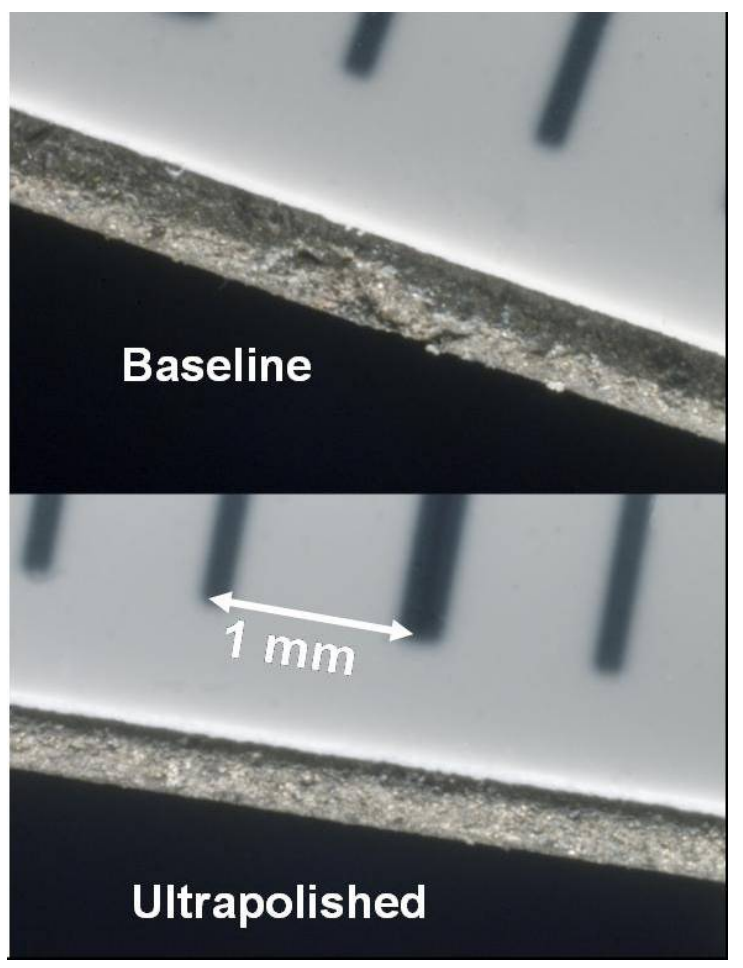

Figure 8. Magnified photograph of rotor 67 leading edge before and after ultrapolishing. 


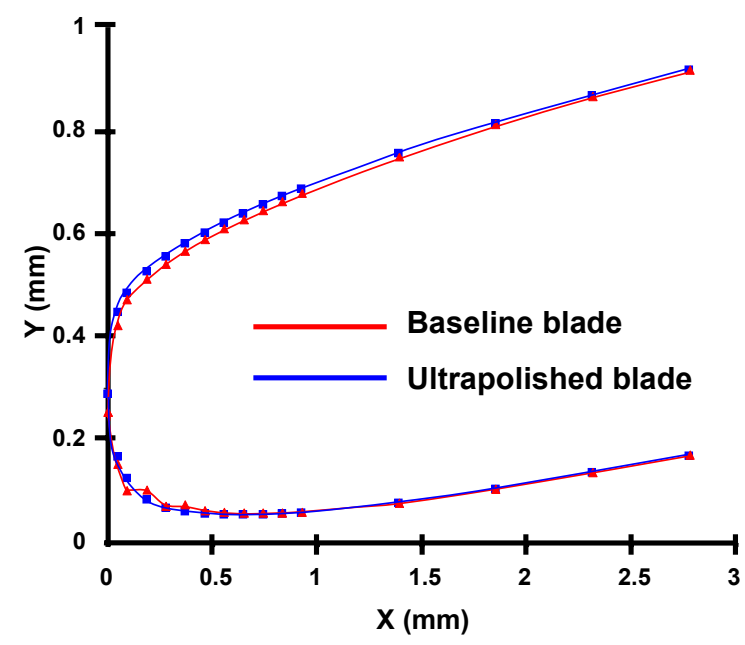

Figure 9. Measured blade leading edge profile before and after ultrapolishing.

well within the transonic region, i.e., relative inlet Mach number at design speed equal to 1.15. A composite blade shape for the baseline and ultrapolish blades was derived by averaging the measurements acquired from the 22 individual blades by a coordinate measuring machine at 70 percent span for pre- and post-polished cases. These composite blade profiles are shown in Figure 9, where no significant difference in leading edge shape can be seen. The coordinate measuring machine accuracy is on the order of $0.005 \mathrm{~mm}$, which is smaller than the data point symbol size in Figure 9. Note that the ultrapolished blade is actually thicker than the baseline blade near the leading edge because the ultrapolish process removed a small amount of material from the nose of the blade, thus effectively blunting the nose of the airfoil.

From Figure 5, it can be seen that there are two data points at design speed for the baseline and ultrapolished cases that have the nearly same corrected mass flow of $33.56 \mathrm{~kg} / \mathrm{sec}$ (74 $\mathrm{lb} / \mathrm{sec}$ ). This means that inlet-air-angles and inlet-relative Mach numbers are the same for both cases. However, there is a measured difference of $0.65 \%$ in efficiency between these points (see Figure 6) due to either surface finish or leading edge shape.

A numerical analysis of the flow over the pre- and post-polish composite profiles was performed for this mass flow rate using the quasi three-dimensional Navier-Stokes solver developed by Chima [7]. This code has previously been used to predict stream tube loss coefficient for the transonic fan of a large production high-bypass turbofan engine. The computation using the code predicted measurement within $\Delta \bar{\omega}=0.0003$ [8].

The relative inlet-air-angle and Mach number at $70 \%$ span was deduced from the measured inlet total and static pressure, plenum temperature and rotational speed. The outlet static to inlet total pressure ratio was adjusted to minimize the massflow residual, $\Delta \dot{m}$. The results are shown in Figure 10 and Table 1 .

It can be seen that the inlet and outlet Mach numbers, flow angles, total pressure loss coefficients and surface Mach

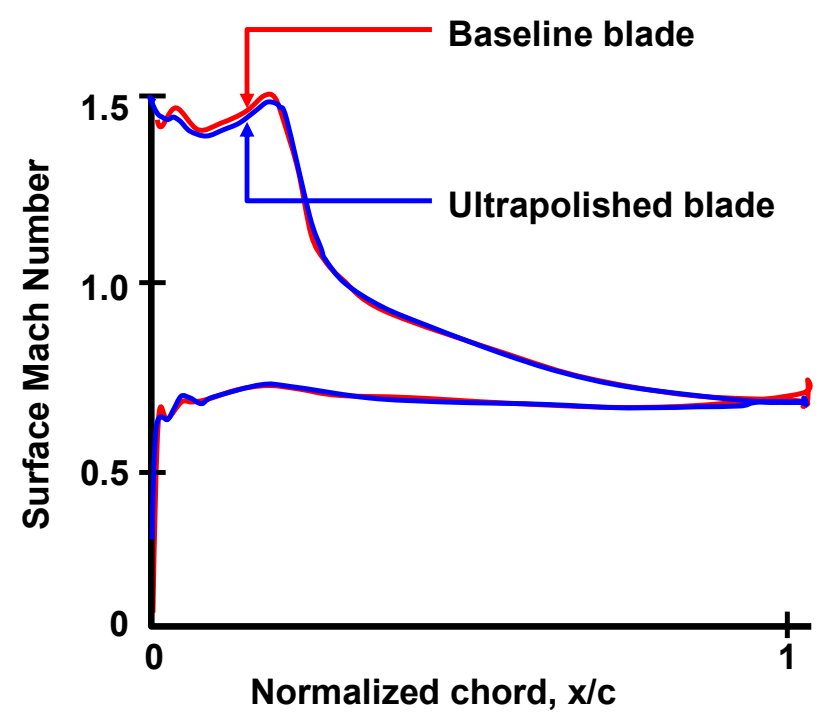

Figure 10. Comparison of predicted surface Mach number distribution at $70 \%$ span from the hub at design speed using blade geometry as measured before (baseline) and after ultrapolishing.

number distributions are essentially the same. The two main performance parameters, total pressure loss coefficient, $\bar{\omega}$, and flow turning, $\theta$, are slightly different. The difference between computed loss coefficients is $\Delta \bar{\omega}=0.11798-0.11624=.00174$. From aerothermodynamic analysis and industrial experience it is known that a $1 \%$ change in blade element loss coefficient over a high pressure compressor leads to approximately $1 \%$ change in adiabatic efficiency. Therefore, the efficiency increase predicted by the quasi three-dimensional analysis due to airfoil leading edge changes after ultrapolishing is 0.00174 or $0.174 \%$. This is about one fourth of the measured improvement in efficiency. The predicted difference in flow deflection before and after ultrapolishing is $0.3^{\circ}$, which is well within the manufacturing tolerance of $\pm 1^{\circ}$ for Rotor 67 blading. Therefore, we conclude that the efficiency improvement after ultrapolishing shown in Figure 6 at design speed is due to the surface finish change.

\begin{tabular}{|c|c|c|}
\hline Parameter & Baseline & Ultrapolish \\
\hline$M_{1}$ & 1.15 & 1.15 \\
\hline$\beta_{1}(\mathrm{deg})$ & 65.6 & 65.6 \\
\hline$\beta_{2}(\mathrm{deg})$ & 57.9 & 57.7 \\
\hline$\theta(\mathrm{deg})$ & 7.6 & 7.9 \\
\hline $\bar{\omega}$ & 0.11798 & 0.11624 \\
\hline$\Delta \dot{m}(\%)$ & 0.1784 & 0.03264 \\
\hline
\end{tabular}

Table 1. Summary of Rotor 67 blade element performance predictions for the baseline and ultrapolished geometry at $\mathbf{7 0 \%}$ of span from the hub at $100 \%$ speed 


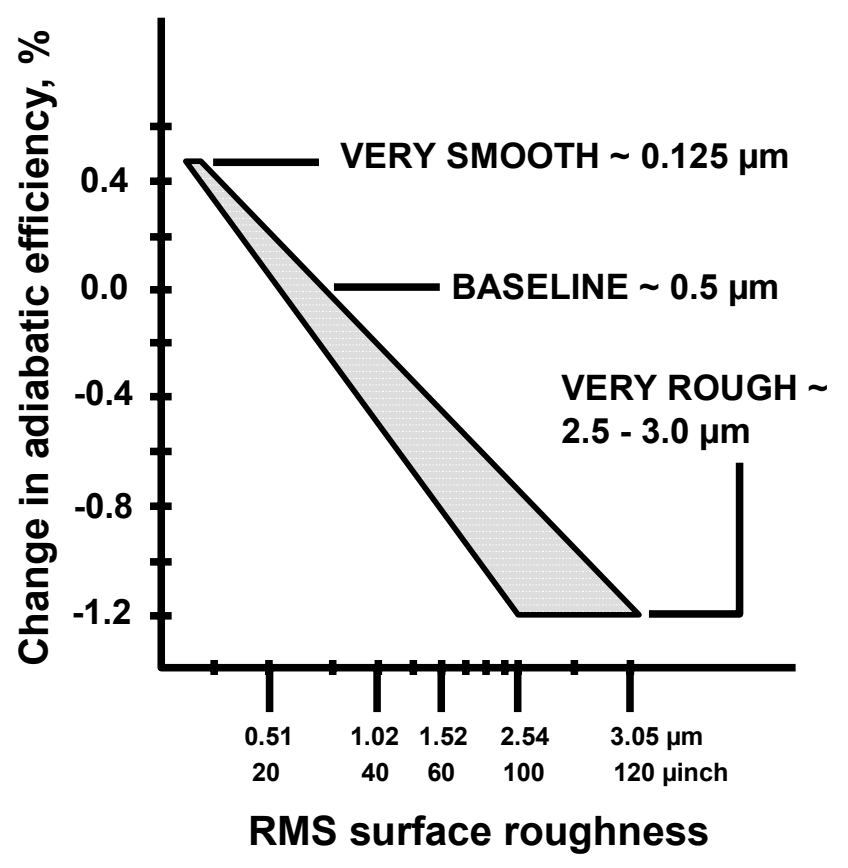

Figure 11. Approximate variation of adiabatic efficiency with surface finish for transonic rotors.

Suder et al [1] measured the efficiency change of a transonic core compressor rotor when surface roughness was increased above the industry-standard surface finish level of 0.5-0.6 $\mu \mathrm{m}$. In the present work we have investigated the efficiency change of a transonic fan rotor when the surface roughness level was decreased below industry-standard levels. We have found that these results are in line with one another as shown in Figure 11, which combines the efficiency changes measured by Suder with those measured in the present work. This semi-logarithmic plot shows the trend in adiabatic efficiency change with surface finish for transonic rotors.

As blades foul in service, the efficiency of the compression system eventually drops off. The ability of a rotor to retain the ultrapolish efficiency gain in service is therefore a valid concern. We assessed this issue by checking the performance of this rotor after the completion of a test program that followed the present work. The rotor was operated for 13 months in the follow-on program during which it accumulated 66 hours ( 4000 minutes) of operation at design speed. Throughout this follow-on program, the rotor was supplied with atmospheric air, filtered to $10 \mu \mathrm{m}$. We found no measurable difference in efficiency compared to the initial ultrapolished performance.

A commercial aircraft engine operates at full-speed only during the takeoff climb and during thrust reversal at landing.

Furthermore, there are substantially fewer atmospheric particles that can foul blades above 10,000 feet. A commercial engine therefore spends only 4-5 minutes per flight at design speed at altitudes where atmospheric particulates are a concern. The 4000 minutes of operation accumulated by the rotor before the performance was rechecked therefore represent 800-1000 cycles.

\section{CONCLUSIONS}

NASA Rotor 67 has been tested with an industry-standard surface finish of $0.5 \mu \mathrm{m}$ ( 20 microinches), ultrapolished to a $0.125 \mu \mathrm{m}$ (5 microinch) finish, and retested. An approximate increase in efficiency of $0.5 \%$ was measured for the ultrapolished rotor near maximum efficiency at design speed.

An increase in efficiency on the order of $0.5 \%$ across the fan and compressor reduces the exhaust gas temperatures (EGT) by $5^{\circ}-8^{\circ} \mathrm{C}$, resulting in increased time in service. A typical medium-size turbofan engine such as the PW2037 or the CFM56 burns between 1.5 and 2 million gallons of fuel per year in regular airline service [9]. At present day fuel prices it would take 3-4 months to pay back the cost of ultrapolishing if the process yields a $0.5 \%$ reduction in fuel burned. After the payback period, the fuel cost savings would be $\$ 7,500-\$ 10,000$ per engine per year (at a fuel cost of one dollar/gallon).

\section{ACKNOWLEDGEMENTS}

The authors would like to thank Mr. Rick Brokopp, Mr. Helmi Abulaban, and Mr. John Jones for supporting the installation and testing of Rotor 67 in the NASA-Glenn Axial Compressor Test Facility, and Dr. Randy Chriss for performing the measurement error analysis. The first author would like to thank Airfoil Technologies International for their financial support. The financial support of the NASA Ultra-Efficient Engine Program for this research is also gratefully acknowledged.

\section{REFERENCES}

1 Suder, K.L., Chima, R.V., Strazisar, A.J., and Roberts, W.B., 1995, "The Effect of Adding Roughness and Thickness to a Transonic Axial Compressor Rotor," ASME Journal of Turbomachinery, Vol. 117, pp. 491505.

2 Koch, C.C., and Smith, L.H., 1976, "Loss Sources and Magnitudes in Axial Flow Compressors," ASME Journal of Engineering for Power, Vol. 98, No. 3, pp. 411-424.

3 Cunnan, W.S., Stevens, W., and Urasek, D.C., 1978, "Design and Performance of a 427 Meter-perSecond-Tip Speed Two-Stage Fan Having a 2.40 Pressure Ratio.” NASA TP-1314.

$4 \quad$ Urasek, D.C., Gorrell, E.T., and Cunnan, W.S., 1979, "Performance of Two-Stage Fan Having Low-AspectRatio, First-Stage Rotor Blading," NASA TP-1493.

5 Pierzga, M.J., and Wood, J.R, 1985, "Investigation of the Three Dimensional Flow Field Within a Transonic Fan Rotor: Experiment and Analysis,' ASME Journal of Engineering for Gas Turbines and Power, Vol. 107, No. 2, pp. 436-449.

6 Roberts, W.B., 1995, “Advanced Turbofan Blade Refurbishment Technique," Technical Brief, ASME Journal of Turbomachinery, Vol. 117, pp. 666-667. 
7 Chima, R.V., 1987, "Explicit Multigrid Algorithm for Quasi-Three-Dimensional Viscous Flows in Turbomachinery," AIAA Journal of Propulsion and Power, Vol. 3, No. 5, pp. 397-405.

8 Roberts, W.B., 1994, "The Effect of Recontouring GE CF6-80C2 Fan Blades," FAR Technical Note prepared for Sermatech International and KLM Royal Dutch Airlines.

9 Delta Airlines, 2004, Private communication with Mr. James Justice, Performance Engineering.

\section{NOMENCLATURE}

s/c space/chord ratio

$M_{1} \quad$ inlet relative Mach number

$\mathrm{X}$ distance along the chord line

Y distance normal to the chord line

PR total pressure ratio

PS pressure surface

SS suction surface

TSFC thrust-specific fuel consumption

$\Delta \dot{m} \quad$ massflow residual, quasi three-dimensional calculation

$\beta_{1} \quad$ inlet relative air angle

$\beta_{2} \quad$ exit relative air angle

$\theta \quad$ airflow turning through the blading

$\bar{\omega} \quad$ total pressure loss coefficient 